\title{
Do we need to develop a more relevant conservation literature?
}

\author{
E.J. Milner-Gulland, Martin Fisher, Stephen B rowne, Kent H. Redford \\ MARJorie SPENCER and WiLliam J. SutherLand
}

The rationale of conservation science is to provide a scientific basis for conservation action but this can only occur if conservation management is actually influenced by this science and if the science provides answers to managementrelevant questions. One of the main roles of conservation journals is to provide this scientific foundation. However, many commentators have highlighted the missing link between research published in these journals and management decisions (e.g. Sutherland et al., 2004): the stereotype is of conservation practitioners basing their actions on personal experience and anecdote whilst scientists talk only amongst themselves about their published articles. Do we, therefore, need to develop a more relevant literature to ensure that conservation science does actually form the basis for conservation practice? The question comes from both sides-how can the knowledge and understanding from conservation practice become better represented in the scientific literature and how can we ensure that pertinent scientific analyses are actually used to improve practice? Although the problem is general, there is a related issue of ensuring that the linkage between science and practice is strengthened in developing countries, where many of the conservation actions are being undertaken and where capacity to publish in, and access, the international scientific literature is often severely lacking.

To promote a debate on this and related questions we organized a workshop, Improving the conservation impact of scientific publishing, at the July 2009 Society for Conservation Biology annual meeting in Beijing. In our various roles as academic researchers, conservation practitioners, journal editors and publisher we wished to seek the views of a cross-section of the conservation community-to reflect on the role of the conservation literature, determine whether others echo our view that this literature is failing conservation, seek any differing points of view, and map an action plan to address the situation. The Beijing meeting offered the perfect opportunity for this wider consultation.

To set the scene we gave a brief presentation of the main findings from a recent study (Campbell et al., 2010) on the conservation impact of published research. A survey of authors of all the species-based research articles published in five major conservation journals (Animal Biology, Biodiversity and Conservation, Biological Conservation, Conservation Biology, Oryx) during 2000-2005 found that c. $50 \%$ of articles had evidence of implementation of research findings. Practical implementation was related to a number of factors: having a non-academic corresponding author, whether the study was part of a long-term targeted conservation programme rather than pure research and had been undertaken with local NGO support, whether concrete recommendations were made for the use of the article's findings, and if there had been dissemination of results in forms other than the article. The means of dissemination most strongly linked to implementation involved communities and local government. This suggests that articles with practical conservation impact are not the main product of a research project but are used by authors as part of a suite of approaches to dissemination and to gain credibility for the recommendations made.

Articles in all journals except Oryx were mostly focused on conservation issues in developed countries. Only $37 \%$ of articles on developing country conservation issues had a corresponding author resident in those countries, compared to $88 \%$ in developed countries. Thirty percent of developing country articles had no national of the study country in the author list. Thus authors in the international conservation literature remain an elite minority, generally with high-level English language skills and predominantly working in North America, Europe and some of the Englishspeaking countries of the Southern Hemisphere. Clearly, the missing link between research published in international conservation journals and implementation of conservation action is greater in developing countries, where the need for scientifically informed management is also arguably higher.

The workshop was very well attended and from the lively discussion it seemed that the subject had struck a chord with many of the attendees. There were calls for the development of a conservation impact factor to complement the scientific impact factors that are so influential in driving authors' publication decision-making. The key to improving the situation, it was felt, was the proper integration of science and management from the start, rather than science trying to influence management after the fact-funding that explicitly requires collaboration between academics and practitioners is a powerful incentive for this to take place. Mention was also made of the mismatch between the questions deemed interesting by scientists and by managers, and the idea of asking managers what questions they actually want answers to was mooted (as in Sutherland et al., 2009). However, a note of caution was struck: should every article have a direct impact on implementation, rather than contributing to a body of evidence that can then be synthesized to provide robust 
answers to management questions (e.g. Pullin et al., 2009)? There could be a danger of swinging pendulum-like between implementation approaches on the basis of each new analysis.

The group also discussed the set of general issues concerning communication and capacity building, highlighting the importance of proactive and transparent information exchange, and that language can be a major barrier, both for readers and authors. If we want to have true engagement of all who practice conservation and research conservation issues, rather than monopolization of conservation publishing by the English-speaking elite of the rich world, there needs to be a major, concerted effort to improve capacity. This needs to start with the formulation of project ideas and funding applications and run through the research process. Just tackling the imbalances at the point of the article, as an end product, will have limited success.

In offering the workshop we were aiming for a heightened awareness amongst participants of the importance of addressing the divide between scientists and practitioners, the barriers to achieving this through the scientific literature, and the potential of a range of approaches to improving the situation. After 30 minutes of discussion it was clear there was much still to debate. One attendee suggested that we create an online forum to allow more of the workshop attendees to comment and thus also open the discussion to a wider audience. This will be helpful in the longer term as a means of communication and capacity building for those interested in improving the dissemination of research results through the scientific literature, and is now available at www.oryxthejournal.org. The forum will be prefaced by this commentary and will remain open for as long as it serves a useful purpose-we invite all interested conservation researchers and practitioners to add their comments.

We believe that the mismatch between science and practice is a serious constraint to effective conservation. We also feel that the continuing lack of capacity in developing countries to access the scientific literature, either as readers or as authors, is both inequitable and a lost opportunity for global science. As journal editors and publisher we control communication through peer-reviewed conservation science and we bear a responsibility to act to improve this situation. The workshop was a step towards acknowledging the problem and an opportunity to consult our colleagues on approaches to tackling it. Other initiatives, such as the writing workshops for developing country scientists offered by Oryx and the Journal of Applied Ecology's Think Global-Act Local conferences (Memmott et al., 2010), need to be ramped up. The growing possibilities for rapid global communication bring the prospect of true collaboration between scientists and practitioners tantalisingly close-as long as we have the imagination and commitment to embrace them.

E.J. MILNER-GULLAND Imperial College London, UK, and Journal of Applied Ecology

MARTIN FISHER Fauna \& Flora International, Cambridge, UK, and Oryx-The International Journal of Conservation

StePHEN BRowne Fauna \& Flora International, Cambridge, UK

KENT H. REDFORD Wildife Conservation Society New York, USA, and Conservation Biology

MARJORIE SPENCER Wiley-Blackwell, UK

William J. SutherLAND Conservation Science Group, Department of Zoology, University of Cambridge, UK, conservationevidence. com and Conservation Letters

\section{References}

Campbell, A., Fisher, M. \& Milner-Gulland, E.J. (2010) Does research published in the scientific literature have any conservation impact? Oryx, 44, in press.

Memmott, J., Cadotte, M., Hulme, P., Kerby, G. \& MilnerGulland, E.J. (2010) Editorial: Putting applied ecology into practice. Journal of Applied Ecology, 47, in press.

Pullin, A.S., Knight, T.M. \& Watininson, A.R. (2009) Linking reductionist science and holistic policy using systematic reviews: unpacking environmental policy questions to construct an evidencebased framework. Journal of Applied Ecology, 46, 970-975.

Sutherland, W.J., Pullin, A.S., Dolman, P.M. \& Knight, T.M. (2004) The need for evidence-based conservation. Trends in Ecology \& Evolution, 19, 305-308.

Sutherland, W.J., Adams, W.M., Aronson, R.B., Aveling, R., Blackburn, T.M., Broad, S. et al. (2009) An assessment of the 100 questions of greatest importance to the conservation of global biological diversity. Conservation Biology, 23, 557-567. 